Check for updates

Cite this: RSC Adv., 2017, 7, 18333

\title{
Proton transfer and esterification reactions in EMIMOAc-based acidic ionic liquids $\uparrow$
}

\author{
Anh T. Tran, Phuoc H. Lam, Alexandra M. Miller, Dustin J. Walczyk, Jay Tomlin, \\ Timothy D. Vaden and Lei Yu (D) *
}

Acetate-based ionic liquids (such as 1-ethyl-3-methylimidazolium acetate, EMIMOAc) have potential applications for $\mathrm{CO}_{2}$ absorption and electrochemical reduction, chemical separations and extractions, and Fischer esterification of alcohols, amines, and starch. Both strong and weak organic acids can be dissolved in EMIMOAC and yield interesting proton-rich acidic ionic liquid solutions. We have used GCMS vapor pressure measurements, spectroscopic methods, calorimetry, and viscosity/conductivity measurements to investigate the properties and reactions of various acids dissolved in EMIMOAc. Unique proton transfer and esterification reactions are observed in many of these acidic solutions with carboxylic acids or sulfonic acids as solutes. Some acids react with the acetate anion to produce acetic acid, which provides a measure of acid strength in ionic liquid solvents. In addition, we observed an esterification reaction that might involve the imidazolium cation and the acetate anion to yield methyl acetate.

Received 6th January 2017

DOI: $10.1039 / c 7 r a 00204 a$

rsc.li/rsc-advances

\section{Introduction}

In a previous report, ${ }^{1}$ we have summarized the advancements of using acetic acid/acetate-based ionic liquids (ILs) for Fisher esterification reactions ${ }^{2-15}$ and $\mathrm{CO}_{2}$ absorption and electrochemical reduction. ${ }^{\mathbf{1 6 - 2 0}}$ Fischer esterification reactions, which are used in the chemical, food, agriculture, and petroleum industries, usually require homogeneous acidic catalysts that can be neutralized after use. Acidic ionic liquids (AILs) can be used as dual solvent-catalysts with improved yields and catalytic activities., ${ }^{3,21}$ Imidazolium acetates are very good solvents for $\mathrm{CO}_{2}$ absorption and electrochemical reduction. ${ }^{16-20} \mathrm{CO}_{2}$ electrochemical reduction produces hydrocarbons when Brønsted acids are present in the solution. The acetate anion also plays an important role in $\mathrm{CO}_{2}$ capture and solvation. ${ }^{22,23}$ When $\mathrm{CO}_{2}$ is dissolved in the IL 1-ethyl-3methylimidazolium acetate (EMIMOAc), a strong interaction between the $\mathrm{CO}_{2}$ molecules and the $\mathrm{OAc}^{-}$anions results in higher $\mathrm{CO}_{2}$ solubility and a lower Henry's Law constant. ${ }^{23-25}$ Acetate-based ILs have also been used for chemical separations such as HF extraction from petroleum products $^{26}$ and metal extraction. ${ }^{27}$ Broadly speaking, AILs are also used as catalysts for saponification, acetalization, and alkylation reactions as well as electrolytes for batteries, fuel cells, and capacitors. ${ }^{28}$

In the above applications the unique properties of ILs (nonvolatility, non-flammability, good stability, etc.) provide

Department of Chemistry and Biochemistry, Rowan University, Glassboro, New Jersey o8028, USA. E-mail: yu@rowan.edu

$\dagger$ Electronic supplementary information (ESI) available. See DOI: 10.1039/c7ra00204a significant advantages. The acids added into the AIL solutions are sources of active protons as reactants or catalysts. However, the acids' fundamental properties in acetate ILs have not been carefully and systematically investigated. In this paper, we present the acid and base properties and reactions of a series of acids in the IL EMIMOAc.

The properties of Brønsted acids such as $\mathrm{p} K_{\mathrm{a}}$ values and proton conduction mechanisms have been very well characterized in aqueous solutions. In non-aqueous environments, such as AIL solutions, the solubility, ionization and acid solvation are more complicated than in aqueous solutions. The ability of the IL molecular anions to accept a positively charged proton, resembling the $\mathrm{H}_{2} \mathrm{O} / \mathrm{H}_{3} \mathrm{O}^{+}$molecules in aqueous solutions, plays an important role in the ionization and solvation processes. For example, the aprotic tetrafluoroborate $\left(\mathrm{BF}_{4}{ }^{-}\right)$anion cannot accept a proton while the bis(trifluoromethylsulfonyl)imide (TFSI) anion can as a weak base. Hence, $\mathrm{H}^{+}$solvated by $\mathrm{BF}_{4}{ }^{-}$ anions is not observed in $\mathrm{BMIMBF}_{4}$ AILs; in solutions with very limited water, $\mathrm{H}_{2} \mathrm{O}$ is protonated to form $\mathrm{H}_{3} \mathrm{O}^{+}$ions which are then solvated by the IL molecular ions. ${ }^{29}$ In TFSI-based ILs, ${ }^{30,31}$ the TFSI anion can be protonated by strong acids dissolved in AIL solutions. When the strong acid HTFSI is dissolved in TFSI-based ILs, a "bridged-proton" structure is observed in which the $>\mathrm{N}-\mathrm{H}$ from the HTFSI molecule bonds directly to the imide nitrogen of the TFSI anion in an $\mathrm{N}-\mathrm{H}-\mathrm{N}$ configuration. The addition of stronger acids such as sulfonic acids may interrupt this existing $\mathrm{N}-\mathrm{H}-\mathrm{N}$ "bridged-proton" structure.

We recently reported the absence of acid ionization or any evidence of acetate protonation, proton transfer, or bridged proton structure in an acetic acid - EMIMOAc AIL solution. ${ }^{1}$ 
This is not surprising since acetic acid is moderately weak even in its aqueous solutions. Stronger acids may behave differently, either by proton-transfer to the anion or different reactions with the IL molecular ions. In this paper, we investigate the properties AIL solutions of a series stronger acids (in terms of $\mathrm{p} K_{\mathrm{a}}$ values in their aqueous solutions relative to acetic acid) in EMIMOAc using vapor pressure, conductivity, viscosity, calorimetric, and spectroscopic measurements. The acids that have been dissolved in the EMIMOAc are carboxylic acids (formic acid, acetic acid, propionic acid), sulfonic acids (methyl sulfonic acid, camphor sulfonic acid, dodecylbenzenesulfonic acid), sulfuric acid $\left(\mathrm{H}_{2} \mathrm{SO}_{4}\right)$, phosphoric acid $\left(\mathrm{H}_{3} \mathrm{PO}_{4}\right)$, tetrafluoroboric acid $\left(\mathrm{HBF}_{4}\right)$, lactic acid, citric acid, malic acid, oxalic acid, and trichloroacetic acid $\left(\mathrm{Cl}_{3} \mathrm{CCOOH}\right)$. We observed proton transfer reactions in these AILs from several acids to acetate to produce acetic acid. Therefore, the acetate can be an indicator to qualify the relative strengths of acids in ILs by measuring the extent of the proton transfer reactions. Further, we observed an interesting esterification reaction that may involve the imidazolium cation in the imidazolium-based AIL systems.

\section{Experimental}

\section{Materials}

EMIMOAc (>95\%) was purchased from IoLiTec GmbH. The IL was degassed and dried in vacuum oven at $\sim 60{ }^{\circ} \mathrm{C}$ overnight prior to use. The IL $N$-butylpyridinium acetate (BPyOAc) was prepared by reacting $N$-butylpyridinium bromide with lead acetate in an aqueous solution followed by removal of the $\mathrm{PbBr}_{2}$ precipitate, evaporation of water at $\sim 50{ }^{\circ} \mathrm{C}$, and drying in a vacuum oven. All other chemicals were purchased from Sigma-Aldrich and used as received. Acid/EMIMOAc solutions were prepared by carefully measuring (pipetting or weighing) the two components with desired volume or mass ratios. Molarities and molar fractions of acids were calculated based on the measured volume/mass ratios and density values of pure acids and EMIMOAc. The solutions were stored in capped containers for all experimental measurements.

\section{Conductivity, viscosity, thermodynamic, vapor pressure, and spectroscopic measurements}

Conductivities of pure ILs and AIL solutions were measured by an AC Mode Traceable ${ }^{\mathrm{TM}}$ conductivity meter at a constant frequency of $3 \mathrm{kHz}$ with a pair of parallel Pt plate electrodes and a temperature probe. The cell constant is designed to be unity. The cell was calibrated by standard solutions with conductivities of 1 and $10 \mathrm{mS} \mathrm{cm}^{-1}$, respectively, prior to the measurements. The conductivity was measured at approximately $23{ }^{\circ} \mathrm{C}$ (room temperature in our laboratory). The built-in temperature probe in the conductivity meter allows the simultaneous reading of conductivity and temperature values. The viscosities of pure ILs and AIL solutions were measured by a Brookfield ${ }^{\circledR}$ rotational viscometer with a built-in temperature probe. All measurements were performed at spindle rotation speed of 2$4 \mathrm{rpm}$ and share rate of $15-30 \mathrm{~s}^{-1}$. Sample temperatures were controlled by circling water from a thermostat. The instrument was calibrated by mineral oil viscosity standards of $20 \mathrm{cP}$ and $200 \mathrm{cP}$, respectively, prior to use.

We measured the enthalpy of solution $\left(\Delta H_{\text {sol }}\right)$ by a typical "coffee-cup" calorimeter, as reported previously. ${ }^{32}$ The EMIMOAc and the acids were mixed in a plastic container with volume capacity of about $10 \mathrm{~mL}$. The system was isolated with a rubber stopper and wrapped with aluminum foil and polystyrene foam. The temperature was monitored with time after the acid and EMIMOAc were mixed by a thermocouple connected to a computer. We measured the solution's specific heat capacity by calibrating the system with a pre-heated copper slug. We also calibrated the systematic error (heat loss) by measuring the solution enthalpy of $\mathrm{CaCl}_{2}$ in $\mathrm{H}_{2} \mathrm{O}$. With $\sim 5-10 \mathrm{~mL}$ of total liquid, we estimated $\mathrm{a} \sim 28 \%$ total heat loss when the maximum temperature was reached within several minutes. ${ }^{32}$ The measured $\Delta H_{\text {sol }}$ values were compensated for this $28 \%$ heat loss.

The vapor pressure was quantified using the "headspace" injection technique with a GC-MS system (Agilent 6890N GC, $5973 \mathrm{MS}$, and 7683 Injector). $0.5 \mathrm{~mL}$ of solutions (prepared with different acid:IL molar ratios) were sealed in $2 \mathrm{~mL}$ vials and shaken thoroughly at room temperature for $10 \mathrm{~min}$ to reach liquid-vapor equilibrium prior to injection. $5 \mu \mathrm{L}$ of the vapor in the headspace was injected (splitless) onto the column. The oven temperature was ramped from $35{ }^{\circ} \mathrm{C}$ to $130{ }^{\circ} \mathrm{C}$ during the chromatography. Ions with expected $\mathrm{m} / \mathrm{z}$ were extracted and chromatographic peak areas were used to calculate the vapor pressure.

Fourier transform infrared (FTIR) spectra of all samples were measured with a Varian FTS 7000 FTIR Spectrometer at $1 \mathrm{~cm}^{-1}$ resolution. A thin layer of liquid samples was sandwiched between two ZnSe salt plates. Samples were thoroughly purged by dry air before data acquisition to remove the absorbed moisture. Spectra demonstrated were the average of 16 coadditions.

\section{Results and discussion}

Vapor pressure measures the intermolecular forces of a volatile molecule in its bulk liquid or in its solutions. In IL solutions, the vapor pressure of a volatile solute/solvent reflects the solute solvation interactions and can be used to estimate the solution enthalpy $\left(\Delta H_{\text {sol }}\right){ }^{1}$ Vapor pressure values of different compounds over a solution can be measured by the "headspace" gas chromatography (GC) method. Fig. 1 shows the GC results from EMIMOAc/formic acid $(\mathrm{HCOOH})$ solutions with various molar fractions. Chromatograms in Fig. 1A and integrated peak areas in Fig. 1B show the detection of different AIL solution components as a function of the molar fractions. We can identify three peaks at different retention times at $T_{\mathrm{r}}=2.55 \mathrm{~min}$ (methyl formate, discussed later), $T_{\mathrm{r}}=2.62 \mathrm{~min}$ (formic acid), and $T_{\mathrm{r}}=2.72 \mathrm{~min}$ (acetic acid). These identifications are based on the molecular mass spectra (MS, Fig. S1 $\dagger$ ), compared with the National Institute of Standard and Technology (NIST) reference MS.

The identification of the neutral acetic acid peak suggests a proton transfer reaction between the formic acid and the acetate ion in IL solutions $\left(\mathrm{HCOOH}+\mathrm{CH}_{3} \mathrm{COO}^{-} \rightarrow \mathrm{HCOO}^{-}+\right.$ 

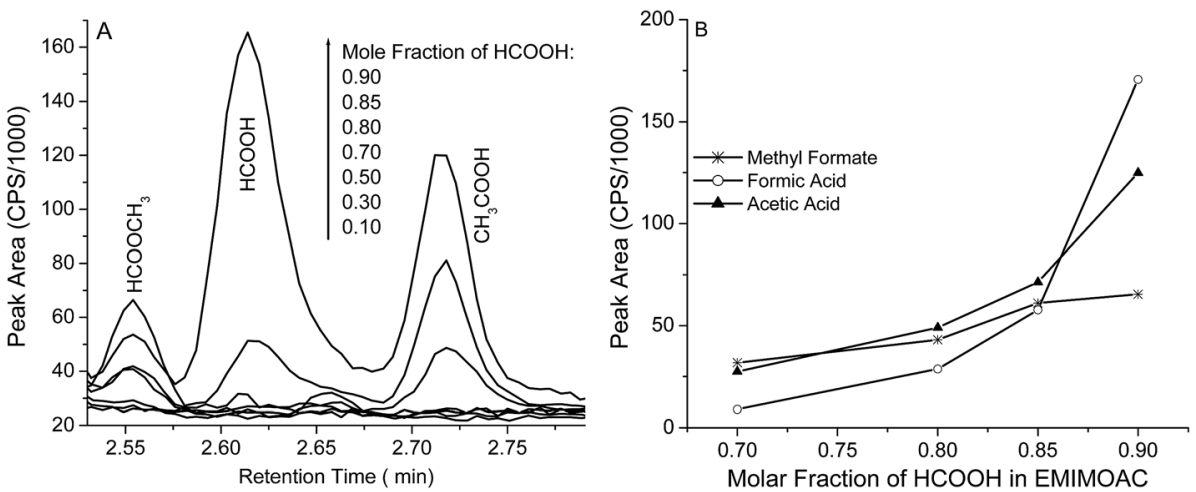

Fig. 1 (A) Headspace GC chromatograms of EMIMOAc/HCOOH solutions with various molar fractions; (B) integrated peak intensities of methyl formate (*), formic acid (O), and acetic acid $(\mathbf{\Delta})$.

$\mathrm{CH}_{3} \mathrm{COOH}$ ). Formic acid is stronger than acetic acid, and therefore the reaction should be thermodynamically productfavored. When weaker carboxylic acids such as propionic acid or butyric acid were added to the EMIMOAc, we did not detect acetic acid in the headspace GC measurements. Notably in Fig. 1, acids are detected at very high formic acid molar fractions $(>0.7)$ in the solutions; at $\mathrm{HCOOH}$ molar fractions lower than 0.7 , acid peaks are not significant. However, we speculate that the proton transfer reaction still proceeds to some extent, but only a limited amount of acetic acid can be produced. Therefore, peaks of both acids are not observable.

In a series of control experiments we performed headspace GC vapor pressure measurements for AIL solutions of carboxylic acids in $\mathrm{BMIBF}_{4}$. In these systems we do not expect proton transfer because the $\mathrm{BF}_{4}{ }^{-}$anion cannot accept protons. Fig. 2 shows the headspace GC results in which relative vapor pressures $\left(p / p_{0}\right)$ are shown versus acid molar fraction. Clearly, the vapor pressures of the polar formic and acetic acid depend on their molar fractions in the AIL solutions: the vapor pressure

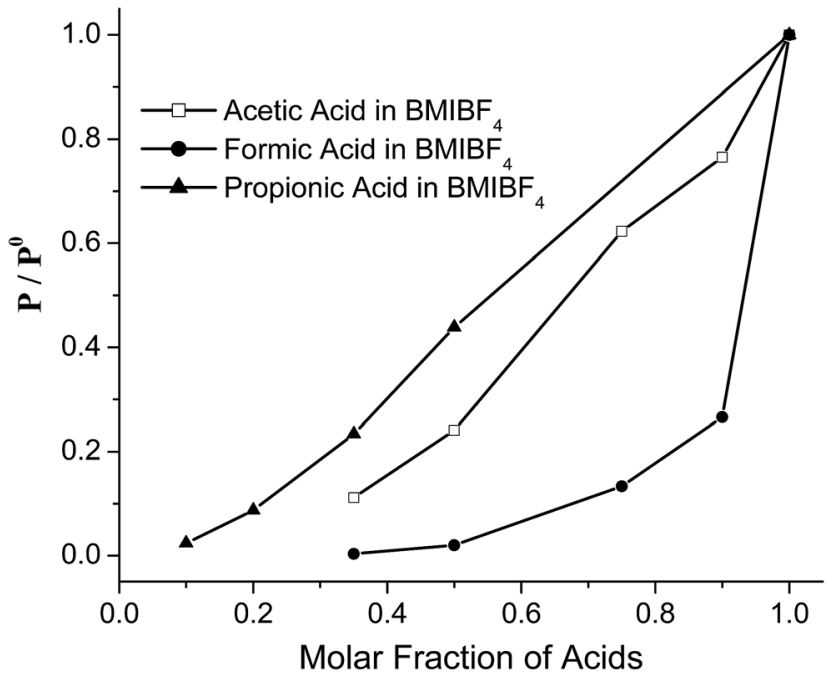

Fig. 2 Relative values of the acid vapor pressure of formic acid ( acetic acid $(\square)$, and propionic acid $(\boldsymbol{\Delta})$ in $\mathrm{BMIBF}_{4}$ solutions as a function of acid molar fractions. values decrease drastically once the $\mathrm{BMIBF}_{4}$ is added into the acids. This also explains that both acids' peaks are absent at lower molar fractions in Fig. 1. The vapor pressure curves in Fig. 2 significantly deviate from Raoult's law, which would predict linear pressure versus molar fraction relationships. Such negative deviations from Raoult's law have also been observed with acetic acid/EMIMOAc solutions ${ }^{1}$ and indicate a large exothermic $\Delta H_{\text {sol }}$. The curve of formic acid deviates the most, which indicates the highest $\Delta H_{\text {sol }}$ and strongest solvation forces among the three acids.

We used a typical "coffer-cup" calorimeter to measure the enthalpy change when formic acid and EMIMOAc are mixed. Fig. 3 shows the temperature change as a function of time when formic acid is mixed with EMIMOAc at a $1: 1$ molar ratio. The temperature rises to as high as $70{ }^{\circ} \mathrm{C}$ and based on our calculations yields a $\Delta H_{\text {sol }}$ of about $-15.1 \mathrm{~kJ} \mathrm{~mol}^{-1}$. When acetic acid is mixed with EMIMOAc at the same molar ratio, the $\Delta H_{\text {sol }}$ value is $-4.9 \mathrm{~kJ} \mathrm{~mol}^{-1}{ }^{1}$ This significantly larger value $\Delta H_{\text {sol }}$ comes from the stronger intermolecular acid-IL interactions as well as the exothermic proton transfer reaction between formic acid and acetate (the esterification reaction discussed later in this paper should also contribute to the total $\left.\Delta H_{\text {sol }}\right)$.

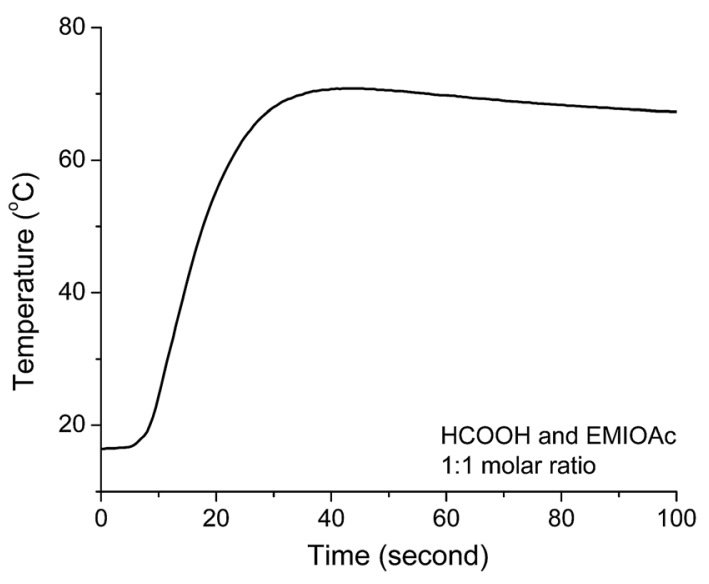

Fig. 3 Time course measurement of the temperature change in the calorimetry experiment when formic acid and EMIMOAc are mixed. 
Fig. 4 shows the results of conductivity and viscosity measurements for the different AIL solutions. The addition of formic acid to the EMIMOAc and $\mathrm{BMIBF}_{4}$ ILs increases the solution conductivities and reduces their viscosities, which validates the Walden's Rule that has been applied in many IL systems. The effects of formic acid on the conductivity and viscosity are more significant compared to other carboxylic acid analogues such as acetic, propionic, and butyric acid, probably due to its smaller molecular weight and hydrodynamic radius. Solution conductivities and viscosities are also affected by the concentrations of each component and their intermolecular interactions. As discussed in our previous reports, IL solution conductivities decrease unanimously with increasing concentrations of ionic solutes such as $\mathrm{Li}^{+}$and $\mathrm{Na}^{+}$salts. ${ }^{32,33}$ With strong acids (strong electrolytes), increasing the acid concentration to create an AIL solution results in increased conductivity at lower concentrations but decreased conductivity at higher concentrations due to reduced acid dissociation (i.e., protonation). ${ }^{31,34}$ On the other hand, IL solution conductivities increase when a non-ionic molecular compound (nonelectrolyte or very weak acid) such as acetonitrile, methanol, or water is mixed with ILs, even though the overall ion concentration reduced..$^{29,32,35,36}$ The addition of formic acid and other carboxylic acids affects the conductivity and the viscosity of the IL solutions in a manner similar to non-electrolytes or weak electrolytes. Based on the above empirical discussion, the effects of carboxylic acids addition, including formic acid, to the ILs are most likely dilution effects. The addition of acid molecules to the ILs may perturb the ion nanoclusters in ILs ${ }^{37,38}$ and help release more "free" solvent ions as charge carriers, which would enhance the solution conductivity and reduce the viscosity. ${ }^{39}$

In addition to the above proton transfer reaction (acid base reaction), we also observed an esterification reaction that was unexpected. In Fig. 1A, we also observed methylformate in formic acid - EMIMOAc AILs with formic acid molar fractions of 0.7 and higher. The methylformate peak intensity increases with higher formic acid concentration. Methylformate is not observed in headspace GC measurements of pure EMIMOAc or formic acid and therefore is the product of a reaction in addition to the proton transfer reaction discussed above (it is not a contaminant in the reactants). Methylformate could be produced via an esterification reaction in the AIL solution. To further investigate this reaction, we studied a series of different acids with EMIMOAc at the maximum acid concentrations dictated by their solubilities. Headspace GC chromatograms, shown in Fig. 5, demonstrate that when methanesulfonic acid (MSA), sulfuric acid (98\% aq.), oxalic acid, phosphoric acid ( $85 \%$ aq.), or tetrafluoroboric acid ( $48 \%$ aq.) are mixed with EMIMOAc, both acetic acid $\left(T_{\mathrm{r}}=2.85 \mathrm{~min}\right)$, product of the proton transfer reactions, and methylacetate $\left(T_{\mathrm{r}}=2.75 \mathrm{~min}\right)$, the esterification reaction product, are observed. However, only acetic acid is observed over the mixture of HTFSI and EMIMOAc.

In Fig. 5B, when lactic acid, camphorsulfonic acid (CSA), trichloroacetic acid, malic acid, dodecylbenzenesulfonic acid (DBSA), or citric acid is mixed with the EMIMOAc, only the peak of methylacetate $\left(T_{\mathrm{r}}=2.75 \mathrm{~min}\right)$ is observed. Acetic acid is either missing or insignificant. To correlate the acid properties, AIL solutions, and the reaction products, we summarize the aqueous $\mathrm{p} K_{\mathrm{a}}$ values, acid molar fractions, and integrated peak intensities of methylacetate and acetic acid peaks in Table 1. It seems that the acid strengths, acid solubilities in the IL, and the presence of water in the mixtures all affect the methylacetate and acetic acid production. However, none of the parameters alone can explain the difference in the reactivities. The GC-MS measurements can only provide the contents of volatile chemicals in the vapor, and not the concentrations of each reactant and product in the bulk liquid mixtures. Therefore, a more quantitative estimate of the equilibrium in the IL/acids mixtures is not available at this point. In several AIL solutions, the absence of the methylacetate or acetic acid is due to either the acid is immiscible with EMIMOAc or not reactive enough, or both. Although it is not isolated from the bulk mixture, the formation of an ester can also be supported by the FTIR spectra of the mixtures, as shown in Fig. 6. We measured the FTIR spectra of pure IL EMIMOAc, MSA, and their equalmolar mixture. In additional to the superimposing of the two spectra of the pure compounds, the mixture spectrum shows peaks at $1223 \mathrm{~cm}^{-1}, 1721 \mathrm{~cm}^{-1}$ and a shoulder at about 1750 $\mathrm{cm}^{-1}$ that may indicate the formation of an ester and a carboxylic acid. ${ }^{40}$

We can conclusively identify the methylacetate as being produced from an esterification reaction in the AIL solutions. The methylacetate is an unanticipated product because typical
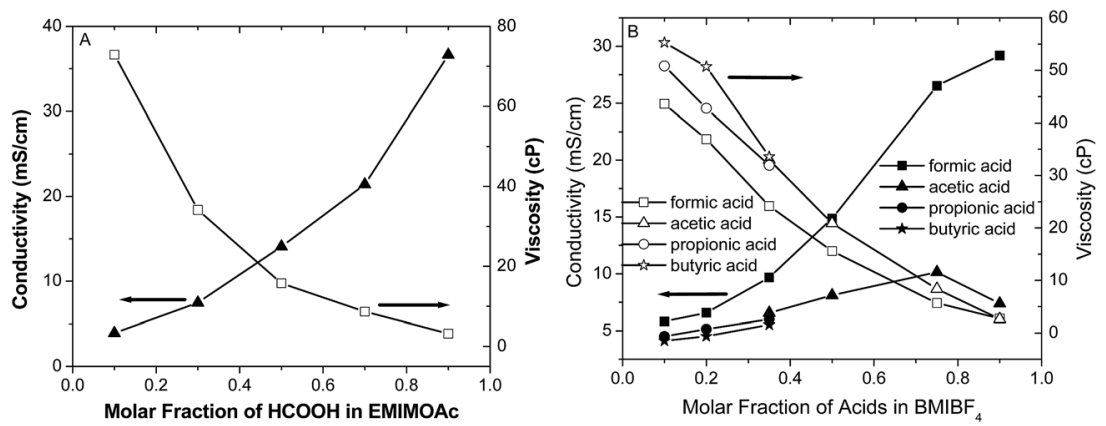

Fig. 4 (A) Conductivity $(-$ ) and viscosity $(\square)$ of $\mathrm{HCOOH}$ in EMIMOAc solutions; (B) conductivity (solid legends) and viscosity (open legends) of formic acid, acetic acid, propionic acid, and butyric acid in $\mathrm{BMIBF}_{4}$ solutions. The errors in conductivity and viscosity values are typically less than $\pm 5 \%$. 

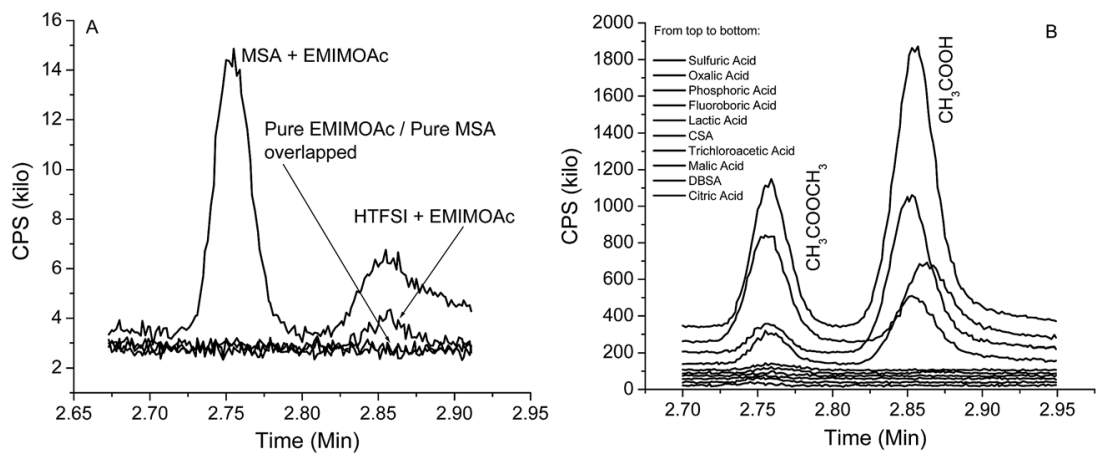

Fig. 5 (A) Headspace-GC chromatograms obtained from MSA only, EMIMOAc only, and EMIMOAc mixtures with MSA and HTFSI; (B) chromatograms obtained from mixtures of EMIMOAC and a series of acids.

Table $1 \mathrm{p} K_{\mathrm{a} 1}$ values, molar ratios, and the integrated peak intensities of GC peaks of various acids mixture with EMIMOAC

\begin{tabular}{lllll}
\hline Acids & $\mathrm{p} K_{\mathrm{a} 1}$ & Molar fraction & Methyl acetate & Acetic acid \\
\hline $\mathrm{H}_{2} \mathrm{SO}_{4}$ & Strong acid & 0.68 & 82934 & 191346 \\
$\mathrm{H}_{3} \mathrm{PO}_{4}$ & 2.15 & 0.65 & 18186 & 92294 \\
$\mathrm{HBF}_{4}$ & -0.4 & 0.51 & 58757 & 31111 \\
Oxalic acid & 1.25 & 0.5 & 10714 & None \\
Citric acid & 3.13 & 0.34 & 8100 & None \\
CSA & 1.2 & 0.438 & 4805 & None \\
DBSA & 0.7 & 0.2 & 5244 & None \\
Lactic acid & 3.86 & 0.45 & 3941 & None \\
Malic acid & 3.4 & 0.26 & 4111 & None
\end{tabular}

esterification reactions require an acetyl group $\left(\mathrm{CH}_{3} \mathrm{COOX}, \mathrm{X}=\mathrm{H}\right.$, $\mathrm{Cl}, \mathrm{Br}$, etc. $)$ and a methyl or methoxyl group $\left(\mathrm{CH}_{3}{ }^{-}\right.$, or $\mathrm{CH}_{3} \mathrm{OX}, \mathrm{X}=$ $\mathrm{H}, \mathrm{Cl}, \mathrm{Br}$, etc.) from the reactants. Certainly the acetyl group comes from the anion of EMIMOAc, especially as adding acids to ILs such as $\mathrm{BMIBF}_{4}$ does not produce esters at detectable levels. However, the source of methyl or methoxyl groups is not clear. To investigate whether the methyl group of the imidazolium cation could be involved, we studied mixtures of formic acid and MSA with ammonium acetate, sodium acetate, and IL $N$-butylpyridinium acetate (BPyOAc). These three salt compounds all have

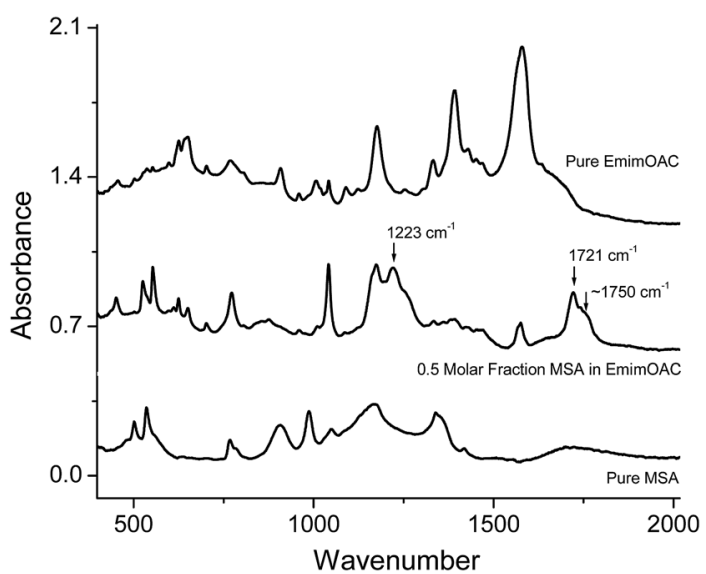

Fig. 6 FTIR spectra of pure EMIMOAc, pure MSA, and their mixtures at molar ratios of $1: 1$. the acetate ion but no methyl or methoxyl groups. Fig. 7 shows headspace GC results for the negative control experiments. Neither methylformate nor methylacetate is observable in Fig. 7. Meanwhile, acetic acid and formic acid are both clearly detected. This indicates that the esterification reaction is not observed without the imidazolium cation and hence the EMIM cation of EMIMOAc is essential in the AIL solutions to produce esters of either methylformate or methylacetate. Dialkylimidazolium ions such as the EMIM cation are considered very stable in acids,

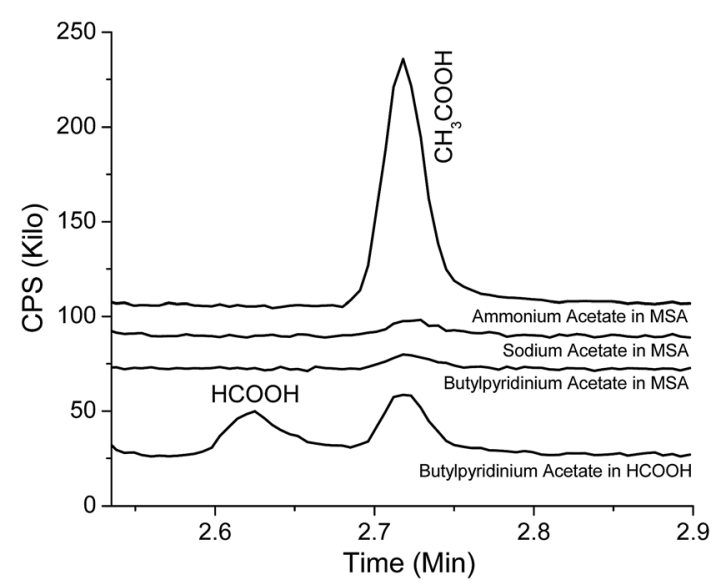

Fig. 7 Chromatograms from the vapor over mixtures of ammonium acetate, sodium acetate, and $\mathrm{N}$-butylpyridinium acetate with formic acid or MSA. 
bases, and organic solvents even at relatively high temperatures. However, it may be involved in reactions in the presence of relatively strong organic acids in the AIL solutions. Details about the mechanism of the reaction is not clear at this point and more experiments are required to elucidate the exact reaction steps. When acetic acid or propionic acid is added into EMIMOAc the esterification product is not observed; likely, an acid stronger than acetic acid is required.

\section{Conclusions}

Experimental results in this paper demonstrated that acetate ion shows Brønsted basic properties in IL solutions. When stronger acids, typical mineral acids, sulfonic acids, or carboxylic acids, are dissolved in IL EMIMOAc, an acid-base (proton transfer) reaction can be observed in the IL solutions. As a result, acetic acid produced by the reaction can be detected in the vapor over the mixture of acids and EMIMOAc. The value of $\Delta H_{\text {sol }}$ when formic acid and EMIMOAc are mixed together is significantly larger than the value of $\Delta H_{\text {sol }}$ when a non-reactive acid is dissolved in EMIMOAc. The higher enthalpy comes from the stronger interaction between the formic acid and the IL and an exothermic acid-base reaction. In addition to the acid-base reaction, we observed an esterification reaction that yields either methylformate (when formic acid is used) or methylacetate (when other acids are used). Several factors may affect the existence or the extent of this esterification reaction. Both the EMIM cation and the acetate anion are essential for the reaction and possibly reactants. This suggests that the imidazolium cation is somewhat unstable in the AIL solutions.

\section{Acknowledgements}

This work is supported by NSF grant CHE-1362493.

\section{References}

1 C. M. Renda, Y. K. Patel, L. R. Henshaw, K. T. Munson, O. C. Fiebig, A. T. Tran, J. Shriver, J. Cruz, L. Yu and T. D. Vaden, J. Mol. Liq., 2016, 216, 710-715.

2 X. X. Ma, Q. B. Zhang, J. Wei, Y. Pan, W. Guan and J. Z. Yang, J. Chem. Thermodyn., 2013, 65, 91-94.

3 D. C. Forbes and K. J. Weaver, J. Mol. Catal. A: Chem., 2004, 214, 129-132.

4 X. Liu, H. Ma, Y. Wu, C. Wang, M. Yang, P. Yan and U. WelzBiermann, Green Chem., 2011, 13, 697-701.

5 B. H. Huang, Z. J. Li, Y. F. Wang, K. Zhang and Y. X. Fang, Acta Chim. Sin., 2008, 66, 1837-1844.

6 J. E. Castanheiro, A. M. Ramos, I. M. Fonseca and J. Vital, Appl. Catal., A, 2006, 311, 17-23.

7 S. Liu, C. Xie, S. Yu, F. Liu and K. Ji, Catal. Commun., 2008, 9, 1634-1638.

8 X. Cui, J. Cai, Y. Zhang, R. Li and T. Feng, Ind. Eng. Chem. Res., 2011, 50, 11521-11527.

9 D. J. Tao, X. L. Zhang, N. Hu, Z. M. Li and X. S. Chen, Int. J. Chem. React. Eng., 2012, 10, A20.
10 J. Fraga-Dubreuil, K. Bourahla, M. Rahmouni, J. P. Bazureau and J. Hamelin, Catal. Commun., 2002, 3, 185-190.

11 A. C. Cole, J. L. Jensen, I. Ntai, K. L. T. Tran, K. J. Weaver, D. C. Forbes and J. H. Davis, J. Am. Chem. Soc., 2002, 124, 5962-5963.

12 R. Irimescu and K. Kato, Tetrahedron Lett., 2004, 45, 523-525.

13 T. L. Greaves and C. J. Drummond, Chem. Rev., 2007, 108, 206-237.

14 J. Cao, B. Qi, J. Liu, Y. Shang, H. Liu, W. Wang, J. Lv, Z. Chen, H. Zhang and X. Zhou, RSC Adv., 2016, 6, 21612-21616.

15 M. Vafaeezadeh and H. Alinezhad, J. Mol. Liq., 2016, 218, 95105.

16 M. B. Shiflett and A. Yokozeki, J. Chem. Eng. Data, 2009, 54, 108-114.

17 M. I. Cabaço, M. Besnard, Y. Danten and J. A. P. Coutinho, J. Phys. Chem. A, 2012, 116, 1605-1620.

18 M. Besnard, M. Isabel Cabaco, F. V. Chavez, N. Pinaud, P. J. Sebastiao, J. A. P. Coutinho, J. Mascetti and Y. Danten, J. Phys. Chem. A, 2012, 116, 4890-4901.

19 Z. F. Zhang, W. Z. Wu, B. X. Han, T. Jiang, B. Wang and Z. M. Liu, J. Phys. Chem. B, 2005, 109, 16176-16179.

20 M. B. Shiflett, D. J. Kasprzak, C. P. Junk and A. Yokozeki, J. Chem. Thermodyn., 2008, 40, 25-31.

21 T. Joseph, S. Sahoo and S. B. Halligudi, J. Mol. Catal. A: Chem., 2005, 234, 107-110.

22 J. A. Steckel, J. Phys. Chem. A, 2012, 116, 11643-11650.

23 W. Shi, C. R. Myers, D. R. Luebke, J. A. Steckel and D. C. Sorescu, J. Phys. Chem. B, 2012, 116, 283-295.

24 W. Shi, R. L. Thompson, E. Albenze, J. A. Steckel, H. B. Nulwala and D. R. Luebke, J. Phys. Chem. B, 2014, 118, 7383-7394.

25 R. S. Bhavsar, S. C. Kumbharkar and U. K. Kharul, J. Membr. Sci., 2012, 389, 305-315.

26 M. V. Velarde, M. Gallo, P. A. Alonso, A. D. Miranda and J. M. Dominguez, J. Phys. Chem. B, 2015, 119, 5002-5009.

27 H. Yang, J. Chen, W. Wang, H. Cui, W. Liu and Y. Liu, Sci. China: Chem., 2016, 59, 532-537.

28 A. S. Amarasekara, Chem. Rev., 2016, 116, 6133-6183.

29 L. Yu, J. Clifford, T. T. Pham, E. Almaraz, F. Perry III, G. A. Caputo and T. D. Vaden, J. Phys. Chem. B, 2013, 117, 7057-7064.

30 K. T. Munson, J. Vergara, L. Yu and T. D. Vaden, J. Phys. Chem. B, 2015, 119, 6304-6310.

31 L. Yu, B. S. Pizio and T. D. Vaden, J. Phys. Chem. B, 2012, 116, 6553-6560.

32 A. Andriola, K. Singh, J. Lewis and L. Yu, J. Phys. Chem. B, 2010, 114, 11709-11714.

33 S. Seki, Y. Ohno, Y. Kobayashi, H. Miyashiro, A. Usami, Y. Mita, H. Tokuda, M. Watanabe, K. Hayamizu, S. Tsuzuki, M. Hattori and N. Terada, J. Electrochem. Soc., 2007, 154, A173-A177.

34 K. T. Munson, J. Vergara, L. Yu and T. D. Vaden, J. Phys. Chem. B, 2015, 119, 6304-6310.

35 V. V. Chaban, I. V. Voroshylova, O. N. Kalugin and O. V. Prezhdo, J. Phys. Chem. B, 2012, 7719-7727.

36 Q. G. Zhang, S. S. Sun, S. Pitula, Q. S. Liu, U. Welz-Biermann and J. J. Zhang, J. Chem. Eng. Data, 2011, 56, 4659-4664. 
37 A. Triolo, O. Russina, H. J. Bleif and E. Di Cola, J. Phys. Chem. $B, 2007,111,4641-4644$.

38 A. Mele, C. D. Tran and S. H. De Paoli Lacerda, Angew. Chem., Int. Ed., 2003, 42, 4364-4366.

39 Y. Yang and L. Yu, Phys. Chem. Chem. Phys., 2013, 15, 26692683.
40 D. Lin-Vien, N. B. Colthup, W. G. Fateley and J. G. Grasselli, The Handbook of Infrared and Raman Characteristic Frequencies of Organic Molecules, Academic Press, 1991, London, UK. 